\title{
Impact of counseling on temporarily deferred donor in a tertiary care hospital, central India: A prospective study
}

$\pi$
0
0
0
0
0
$\frac{T}{T}$

Kumar Alok, Prajapati

Satyendra ${ }^{1}$, Satish $M$.

Sharma ${ }^{2}$, Narayan S. Ingole $^{2}$, Nitin Gangane ${ }^{2}$

Department of Pathology, Government Medical College, Jagdalpur, Bastar, Chhattisgarh, ${ }^{1}$ Assistant Professor, Govt Medical College Jagdalpur, Chhattisgarh, ${ }^{2}$ Department of Pathology, Mahatma Gandhi Institute of Medical Sciences, Sewagram,

Wardha, Maharashtra, India

Address for the Correspondence: Dr. Alok kumar, Department of Pathology, Government Medical College, Jagdalpur, Bastar, Chhattisgarh, India.

E-mail: alokkrlkr@gmail.com

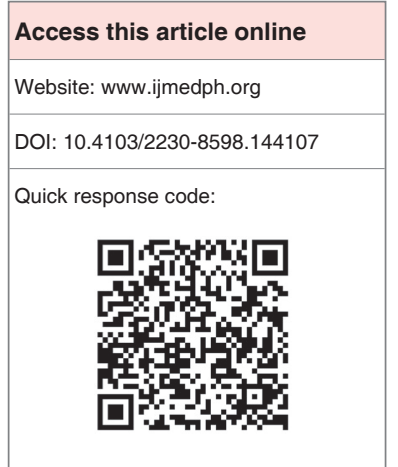

Background: Donors disqualified or rejected from donating blood are known as "deferred" donors. Blood donors are deferred for various reasons. Donors are deferred either temporarily or permanently. To make blood transfusion safe for the patients, many safety measures are undertaken, and the most important is a selection of the suitable blood donors. The rate and reasons of deferral differ from region to region and one center to the other. Aim: The aim of this study is to find out the impact of counseling on temporary donors deferral. Materials and Methods: A total of 271 donors is deferred against 10,853 blood donors recruited on the basis of clinical history and brief medical examination by medical officer during the period of 19 months from $1^{\text {st }}$ of November 2009 to $31^{\text {st }}$ May 2011. Those who were deferred temporarily during this period were counseled regarding the importance of blood donation and asked them to recruit after removal of the temporary causes. Follow-up of these temporarily deferred donors was done for 1 -year. During this period, data collected were analyzed after 1-year of follow-up. Result: Incidence of donor deferral in our study was low. Most common reasons for the donor deferral in our study were alcohol consumption, followed by anemia and then, history of sexual exposure. A total of 124 temporarily deferred donors were recruited for blood donation. Conclusion: Voluntary blood donors are the backbone of blood bank. Deferral of the donors creates negative feelings about blood donation. Education, motivation, and treatment of these deferred donors due to anemia or other temporary deferrals are important aspects in blood banking and hence that these donors can be recruited again. Thus, effective measures need to be initiated to find out the issue of lost donors in terms of numbers and reasons. Hence, it is important to retain the stock of precious blood units lost due to these temporary deferrals.

Key words: Donors, impact of counseling, temporary deferral

\section{INTRODUCTION}

Blood Transfusion Services are the essential part of health care system without which efficient medical care is not possible. ${ }^{[1]}$ However, it requires an adequate supply of safe blood. The National AIDS Control Organization's statistics show that the annual rate of blood donation in India is about 7.4 million units, against the requirement of 10 million units. ${ }^{[2]}$ To protect blood donors and recipients, stringent donor screening criteria are necessary. ${ }^{[3]}$ The aim of this study was to find the impact of counseling on temporary donors deferral.

\section{MATERIALS AND METHODS}

This was a prospective study carried out in the Blood bank of a tertiary care hospital, central India over a period of 19 months from $1^{\text {st }}$ of November 2009 to $31^{\text {st }}$ May 2011. Each donor was selected by a medical officer during this period, based on detailed medical history and brief physical examination of donors with regard to hemoglobin, blood pressure, temperature, and pulse regularity and rate using WHO criteria for donor selection. ${ }^{[1]}$ Detailed information on the donor deferral including the cause of deferral was recorded in donor form. Donors deferred were differentiated according to sex and age group. Temporarily deferred donors during that period were counseled regarding the importance of 
blood donation, and they were informed that they could be recruited for blood donation after removal of the cause. Data were analyzed after 1-year follow-up.

\section{RESULTS}

A total of 10,853 blood donors recruited for blood donations during our study, in which 271 blood donors were deferred on the basis of medical history and physical examination in which 210 were voluntary, and 61 were replacement donors. There were no paid donors in our study. Among total donors in the blood bank, $97.05 \%$ were male, and 2.95\% were female. Almost $78 \%$ were voluntary donors and $22 \%$ were replacement donors. Among voluntary donors, $96.24 \%$ were male, and $3.76 \%$ were female donors as shown in Table 1.

There were total 69 voluntary blood donations camps organized during the study period, male donors constituted $90.38 \%$ of donors and female were $9.62 \%$ as shown in Table 2 .

The donor cards were analyzed for ascertaining the reasons for donor deferral. A total of 271 donors was deferred during the study period, the most common cause was alcoholism, which accounted $65(23.98 \%)$ of deferred donors as shown in Table 3.

Further analysis was done to know the frequency of donor deferral involuntary and replacement donors, and it was observed that deferral was more involuntary than the replacement donors and more in male $(94.44 \%)$ than female $(5.56 \%)$ as shown in Table 4.

Among deferred donors, majority of donors were under the age of 28 years $(35.80 \%)$, followed by those aged $28-38$ years $(29.52 \%)$. No donors were deferred aged above 58 years in our study as shown in Table 5.

108 temporarily deferred donors, after removal of the cause were recruited again after a follow-up 1-year in which all were voluntary donors as shown in Table 6.

In our study, $39.85 \%$ of temporarily deferred donor return for blood donation, in which $62.00 \%$ were $1^{\text {st }}$ time blood donors, and $38.00 \%$ were repeat donors during 1 -year of follow-up period as shown in Table 7.

\section{DISCUSSION}

Deferring or rejecting potential blood donors often leaves the donor with negative feeling about themselves as well as the blood banking system. However, there are definite advantages of eliminating donors with possible risk of disease because, despite the availability of sensitive screening tests to detect HIV infection, blood donors can be infected, but tests are negative if they have been infected for a period of 6 weeks or less. ${ }^{[4]}$

The rate of deferral differs from region to region and sometimes in the same region and one center to another. ${ }^{[5]}$ Deferral incidence was observed by Zou et al. (12.8\%), Sundar et al. (6\%), Rabeya et al. (5.6\%), Lawson-Ayayi and Salmi (10.8\%), Chaudhary et al. (16.4\%), Bahadur et al. (9\%), and Custer et al. $(13.6 \%) .{ }^{[6-12]}$

The lowest reported rate of rejection was by Talonu $\mathrm{T}$ (4\%) in Papua New Guinea and higher rate (8-15\%) was reported by Chaudhary et al., Blumberg et al. and Ranveet et al.. ${ }^{[10,13-15]}$

However, studies by other authors have cited low (5.6-7.1\%) to very high (20-35.6\%) deferral incidence in their donor population, which

\begin{tabular}{lccc}
\multicolumn{4}{l}{ Table 1: Status of donors as per sex and type } \\
\hline Types of donors & Male (\%) & Female (\%) & Total donors (\%) \\
\hline Voluntary donors & $7922(96.24)$ & $310(3.76)$ & $8232(77.79)$ \\
$\begin{array}{l}\text { Replacement } \\
\text { donors }\end{array}$ & $2347(99.9)$ & $03(0.10)$ & $2350(22.21)$ \\
Total & $10269(97.05)$ & $313(2.95)$ & $10582(100)$ \\
\hline
\end{tabular}

$\begin{aligned} & \text { Table 2: Analysis of voluntary blood donation } \\
& \text { camps }\end{aligned}$
\begin{tabular}{lccc}
\hline $\begin{array}{l}\text { Number of camp } \\
\text { organized }\end{array}$ & $\begin{array}{r}\text { Number of blood units } \\
\text { collected }\end{array}$ & $\begin{array}{c}\text { Total donors } \\
\text { (\%) }\end{array}$ \\
\cline { 2 - 3 } & Male (\%) & Female (\%) & \\
\hline 69 & $2041(90.38)$ & $217(9.62)$ & $2258(100)$ \\
\hline
\end{tabular}

\begin{tabular}{lc} 
Table 3: Analysis for donors deferral \\
\hline Reasons for deferral & Numer of deferred donors (\%) \\
\hline Alcoholic & $65(23.98)$ \\
Anemia & $47(17.35)$ \\
Abnormal blood pressure & $28(10.25)$ \\
History of sexual exposure & $35(12.92)$ \\
Underweight & $14(5.16)$ \\
History of TT injection & $13(4.80)$ \\
Past history of blood donation & $11(4.05)$ \\
Underage & $05(1.85)$ \\
History of AIDS & $03(1.10)$ \\
Others & $50(18.45)$ \\
Total & $271(100)$ \\
\hline
\end{tabular}

TT = Tetanus toxoid

\begin{tabular}{lccc}
\multicolumn{4}{l}{ Table 4: Status among deferred donors } \\
\hline Donors & Male (\%) & Female (\%) & Total (\%) \\
\hline Voluntary & 198 & 12 & $210(77.40)$ \\
Replacement & 58 & 03 & $61(22.60)$ \\
Total & $256(94.44)$ & $15(5.56)$ & $271(100)$ \\
\hline
\end{tabular}

\section{Table 5: Age status among deferred donors}

\begin{tabular}{lc}
\hline Age groups (in years) & Number of donors $(\%)$ \\
\hline$<18$ & $05(1.84)$ \\
$18-28$ & $97(35.80)$ \\
$28-38$ & $80(29.52)$ \\
$38-48$ & $47(17.34)$ \\
$48-58$ & $42(15.50)$ \\
$58-62$ & 0 \\
Total & $271(100)$ \\
\hline
\end{tabular}




\begin{tabular}{ll}
$\begin{array}{l}\text { Table 6: Status of recruited donors after a follow-up } \\
\text { of 1-year }\end{array}$ \\
\hline Number of recruited donors & Reasons for temporarily deferral \\
\hline 52 & Alcohol \\
37 & Anemia \\
10 & Underweight \\
9 & Past history of blood transfusion \\
Total donors & $108 / 271=39.85 \%$ \\
\hline
\end{tabular}

\begin{tabular}{lc} 
Table 7: Status of recruited donors \\
\hline Frequency of blood donors & No of donors (\%) \\
\hline First time blood donor & $67(62.00)$ \\
Repeat blood donors & $41(38.00)$ \\
Total donors & $108(100)$ \\
\hline
\end{tabular}

probably reflects the regional diversity and marked variation in whole blood donor eligibility criteria internationally. ${ }^{[8,16-20]}$

With compared to other studies, the overall deferral rate in our study was the lowest, about $2.50 \%$. One of the reasons could be that the predonation interview as well as medical examination was not conducted as strict manner when compared to other places. It will be suggested to the blood bank in the audit report that interview and examination, these to be conducted in more precise manner in. However, if the deferral rate continues to remain low, it means the reason for deferral is not so prevalent in this area as compared to other areas.

In a Saudi Arabian study, ${ }^{[21]} 26.8 \%$ were deferred for consumption of drugs, $15.5 \%$ for low hemoglobin, but only $5.7 \%$ for hypertension. However, a number of other studies showed anemia as the major cause (Arslan 20.7\% and Halperin et al. 46\%). In a study in Trinidad and Tobago, a history of high-risk sexual activity was the most common cause of deferral. ${ }^{[22-24]}$

In India, Bahadur et al. ${ }^{[11]}$ in their study with predominantly replacement donors $(99.4 \%)$ found low $\mathrm{Hb}$ as the most common cause of deferral $(32.9 \%)$. However, second and third most common reasons in their study were low weight $(26.6 \%)$ and history of jaundice/hepatitis $(8.1 \%)$. Similarly, in another Indian study by Chaudhary et al. ${ }^{[10]}$ low weight $(32.3 \%)$ and low $\mathrm{Hb}(18.6 \%)$ were respectively the two most common reasons for the deferral.

Kwa et al. (poor vein and underweight donors), Charles et al. (low $\mathrm{Hb}$ and Hypertension), Zou et al. (travel to the malaria area and miscellaneous blood exposure), and Rabeya et al. (high-blood pressure and medical illness) have cited various other common reasons for deferral in respective study population. ${ }^{[6,8,16,18]}$

In our study, $2.5 \%$ blood donors were deferred on the basis of history as well as clinical examination. Among deferred blood donors, the most common cause of deferral was alcohol consumption $(23.98 \%)$ followed by anemia $(17.35 \%)$. In female donors, the most common cause of deferral was anemia. Among deferred donors, 256 (94.44\%) were voluntary while 15 (5.56\%) were replacement donors. Domen et al. ${ }^{[24]}$ indicate that shared donor deferral registries may be valuable at the local or regional level to prevent deferred blood donors from donating at other blood collection facilities.

Donor self-deferral is valid for reducing the risk of HIV transmission through blood transfusions, and its implementation should be encouraged, when recruiting blood donors. ${ }^{[25]}$

A study by Custer et al. ${ }^{[12]}$ (2004) which shows that the donor deferral has a negative effect on the donor, especially more pronounce with $1^{\text {st }}$ time donors.

A study done by Zou et al. ${ }^{[2]}$ at American Red Cross reported that $22.08 \%$ of temporarily deferred donors returned for blood donation over a span of 3 years. Reich et al. ${ }^{[27]}$ from California observed total of $20.5 \% 1^{\text {st }}$ time donors returned for donations. Custer et al. ${ }^{[28]}$ from California also reported more repeat donors returned for blood donation. According to them depending on the deferral category, $14-31 \%$ of $1^{\text {st }}$ time and $58-90 \%$ of repeat donors returned. The effects of deferral were more pronounced than expected, affecting both $1^{\text {st }}$ time and repeat donors. Blumberg et al. ${ }^{[14]}$ (1982) reported that $13 \%$ of deferred had granted full permission to donate after completion of the deferral period.

As with the above mentioned studies, it was found that the most common cause for temporarily deferral was anemia.

Comparing with other studies, return of temporarily deferred blood donors for blood donation was more (39.85\%) in our study. In our study, more number of $1^{\text {st }}$ time donors reported for blood donation compared to repeat donors. It might be due to counseling of temporarily deferred donor regarding importance of blood donation.

\section{CONCLUSION}

Incidence of donor deferral in our study was low. Most donors were deferred due to temporary causes. The most common reasons for deferral in our study were alcohol consumption, followed by anemia and then, history of sexual exposure.

Voluntary blood donors are the backbone of blood bank. Deferral of the donors creates negative feelings about blood donation. Education, motivation, and treatment of these deferred donors due to anemia or other temporary deferrals are important aspects in blood banking, so that these donors can be recruited again as seen in our study. Thus, effective measures need to be initiated to find out the issue of lost donors in terms of numbers and reasons. It is important to retain the stock of precious blood units lost due to these temporary deferrals.

\section{REFERENCES}

1. Saran RK. Transfusion Medicine technical manual. $2^{\text {nd }}$ ed. Directorate General of Health Services, Ministry of Health and Family Welfare, Government of India. New Delhi: WHO; 2003.

2. Department of AIDS Control Ministry of Health and Family Welfare Government of India Annual Report; 2008-2009. p. 27. 
3. Lim JC, Tien SL, Ong YW. Main causes of pre-donation deferral of prospective blood donors in the Singapore Blood Transfusion Service. Ann Acad Med Singapore 1993;22:326-31.

4. Sawanpanyalert $P$, Uthaivoravit $W$, Yanai $H$, Limpakarnjanarat $K$, Mastro TD, Nelson KE. Donation deferral criteria for human immunodeficiency virus positivity among blood donors in northern Thailand. Transfusion 1996;36:242-9.

5. Galea G, Gillon J, Urbaniak SJ, Ribbons CA. Study on medical donor deferrals at sessions. Transfus Med 1996;6:37-43.

6. Zou S, Musavi F, Notari EP, Rios JA, Trouern-Trend J, Fang CT. Donor deferral and resulting donor loss at the American Red Cross Blood Services, 2001 through 2006. Transfusion 2008;48:2531-9.

7. Sundar P, Sangeetha SK, Seema DM, Marimuthu $P$, Shivanna N. Pre-donation deferral of blood donors in South Indian set-up: An analysis. Asian J Transfus Sci 2010;4:112-5.

8. Rabeya Y, Rapiaah M, Rosline H, Ahmed SA, Zaidah WA, Roshan TM. Blood pre-donation deferrals - a teaching hospital experience. Southeast Asian J Trop Med Public Health 2008;39:571-4

9. Lawson-Ayayi S, Salmi LR. Epidemiology of blood collection in France. Eur J Epidemiol 1999;15:285-92.

10. Chaudhary RK, Gupta D, Gupta RK. Analysis of donor-deferral pattern in a voluntary blood donor population. Transfus Med 1995;5:209-12.

11. Bahadur S, Jain S, Goel RK, Pahuja S, Jain M. Analysis of blood donor deferral characteristics in Delhi, India. Southeast Asian J Trop Med Public Health 2009;40:1087-91.

12. Custer B, Johnson ES, Sullivan SD, Hazlet TK, Ramsey SD, Hirschler NV, et al. Quantifying losses to the donated blood supply due to donor deferral and miscollection. Transfusion 2004;44:1417-26.

13. Talonu T. Causes of volunteer blood donor rejection in Papua New Guinea. P N G Med J 1983;26:195-7.

14. Blumberg N, Shah I, Hoagland J, Shirer L, Katz AJ. Evaluation of individuals deferred from blood donation for medical reasons. Vox Sang 1982;42:1-7.

15. Ranveet K, Basu S, Marwaha N. A Reappraisal of underrlysing causes in donor deferral. Ann Natl Acad Med Sci 2002;38:93-9.

16. Kwa SB, Ong YW, Gaw YN. Blood donor rejects - A study of the causes and rejection rates. Singapore Med J 1966;7:61-8.

17. Tomasulo PA, Anderson AJ, Paluso MB, Gutschenritter MA, Aster RH. A study of criteria for blood donor deferral. Transfusion 1980;20:511-8.
18. Charles KS, Hughes P, Gadd R, Bodkyn CJ, Rodriguez M. Evaluation of blood donor deferral causes in the Trinidad and Tobago National Blood Transfusion Service. Transfus Med 2010;20:11-4.

19. Di Lorenzo Oliveira C, Loureiro F, de Bastos MR, Proietti FA, Carneiro-Proietti AB. Blood donor deferral in Minas Gerais State, Brazil: Blood centers as sentinels of urban population health. Transfusion 2009;49:851-7.

20. Madan N, Qadiri J, Akhtar F. Study of blood donor profile at a tertiary care teaching hospital. J Acad Hosp Adm 2005;17:31-4.

21. Bashawri LA. A review of predonation blood donor deferrals in a university hospital. J Family Community Med 2005;12:79-84.

22. Arslan $\mathrm{O}$. Whole blood donor deferral rate and characteristics of the Turkish population. Transfus Med 2007;17:379-83.

23. Halperin D, Baetens J, Newman B. The effect of short-term, temporary deferral on future blood donation. Transfusion 1998;38:181-3.

24. Domen RE, Grewal ID, Hirschler NV, Hoeltge GA. An evaluation of the need for shared blood donor deferral registries. Int J Qual Health Care 1997;9:35-41.

25. Urwijitaroon Y, Barusrux S, Romphruk A, Puapairoj C, Pakote L. Reducing the risk of HIV transmission through blood transfusion by donor self-deferral. Southeast Asian J Trop Med Public Health 1996;27:452-6.

26. Zou S, Musavi F, Notari EP $4^{\text {th }}$, Fujii KE, Dodd RY; ARCNET Study Group. Prevalence of selected viral infections among temporarily deferred donors who returned to donate blood: American Red Cross blood donor study. Transfusion 2005;45:1593-600.

27. Reich P, Roberts P, Laabs N, Chinn A, McEvoy P, Hirschler N, et al. A randomized trial of blood donor recruitment strategies. Transfusion 2006;46:1090-6.

28. Custer B, Chinn A, Hirschler NV, Busch MP, Murphy EL. The consequences of temporary deferral on future whole blood donation. Transfusion 2007;47:1514-23.

How to cite this article: Alok K, Satyendra P, Sharma SM Ingole NS, Gangane N. Impact of counseling on temporarily deferred donor in a tertiary care hospital, central India: A prospective study. Int J Med Public Health 2014;4:400-3.

Source of Support: Nil, Conflict of Interest: None declared. 